\title{
GIS-mapping ADCP backscatter data to support environmental studies
}

\author{
Roberto Nardini $^{\mathrm{a}}$, Paola Picco ${ }^{\mathrm{b},} *$, Maurizio Demarte $^{\mathrm{c}}$ \\ ${ }^{a}$ Italian Hydrographic Institute, roberto_nardini@marina.difesa.it \\ ${ }^{b}$ Italian Hydrographic Institute, paola.picco@persociv.marina.difesa.it \\ ${ }^{c}$ Italian Hydrographic Institute, maurizo.demarte@marina.difesa.it \\ * Corresponding author
}

Keywords: ADCP, GIS, Mediterranean Sea, Underwater acoustic backscatter data, Zooplankton migrations

Abstract:

The presence and abundance of zooplankton is a key information for marine environmental studies, due to the important role it plays in the trophic chain. Differently from the phytoplankton distribution, that can be remotely observed from satellite, the detection of zooplankton requires a huge effort for in-situ net sampling and acoustic detection.

Several research vessels regularly operate the VM-ADCP (Vessel Mounted Acoustic Doppler Current Profiler) to measure the three-dimensional ocean currents along the track up to a depth of several tenth meters. In addition to velocities data, they also provides the acoustic backscatter data with the same sampling setting. The analysis of the variation of the ADCPs backscatter signal has proved to be useful to identify the presence of zooplankton in the water column, as these instruments operate at frequencies that can be reflected back by the planktonic organisms. The huge amount of acoustic data collected during oceanographic campaigns without additional efforts represents an important source of information that can be of great value for other scientists. As the acoustic data set obtained from a moving vessel during an oceanographic campaign might involve time and space scales that do not completely meet the temporal and spatial resolution required for dedicated zooplankton studies, there is the need for efficient data management tools.

A GIS application has been developed at the Italian Hydrographic Institute for the management, elaboration and mapping of this particular kind of data. It has been developed on QGIS ${ }^{\circledR}$ and tested on the Ligurian Sea (Mediterranean Sea), but it can be extended to any other region.

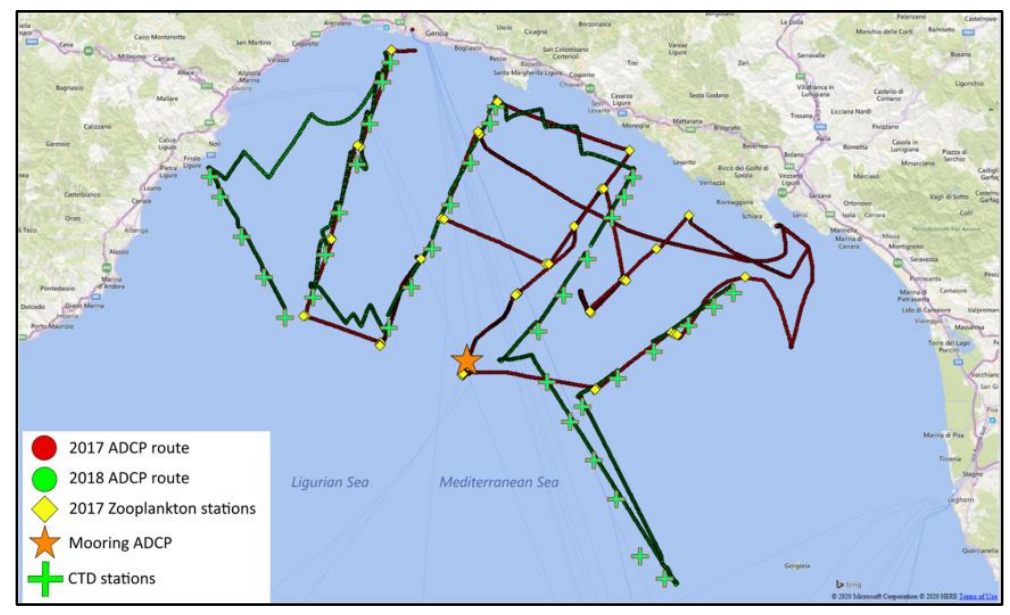

Figure 1. The area considered for the test-case with the route of two selected campaigns and the position of the in situ measurements.

Before starting with the mapping and analysis, the raw echo intensity data is converted into comparable volume backscatter strength values, taking into account the frequency of the instrument and the sampling set up. The high backscatter values due to the bottom reflection are then eliminated by integration with the layer of the high-resolution bathymetry rasters acquired and processed by the Italian Hydrographic Institute. Environmental parameters acquired during the campaing (salinity and temperature profiles) provide additional corrections of the backscatter values along the water column, automatically using the closest profiles both spatially and temporally. 
After processing the raw data, it is then possible to evaluate the relative differences in backscatter at different depths. By selecting two ADCP bins of your choice, you can create two-band multilayer rasters, each band representing the intensity at the bin depth. These geo-referenced rasters are visualized with a false color scale, associating the red color to one bin and the blue color to the second bin. The combinations between these two colors represent the relative backscatter ratio at these two depths: if the presence of backscatter response is predominant on one layer over the other, the color will tend to concentrate on the color of the predominant layer, otherwise it will remain with one intermediate color.

One of the main problems faced when mapping acoustic data sampled from a moving vessels is related to the daily vertical migrations of zooplankton that can involve high depths and changes according to the season and lunar phase. For a correct interpretation of the horizontal distribution, the use of the ephemeris allows to precisely identify the data corresponding to the different phase of the dayligth (dusk, nigth, dawn,day) and of the moon, which are represented in different colours.

False-colour composite using two bands allows to identify zooplankton presence at the different depths, and, combined with day/night maps, they can help to define migration patterns.

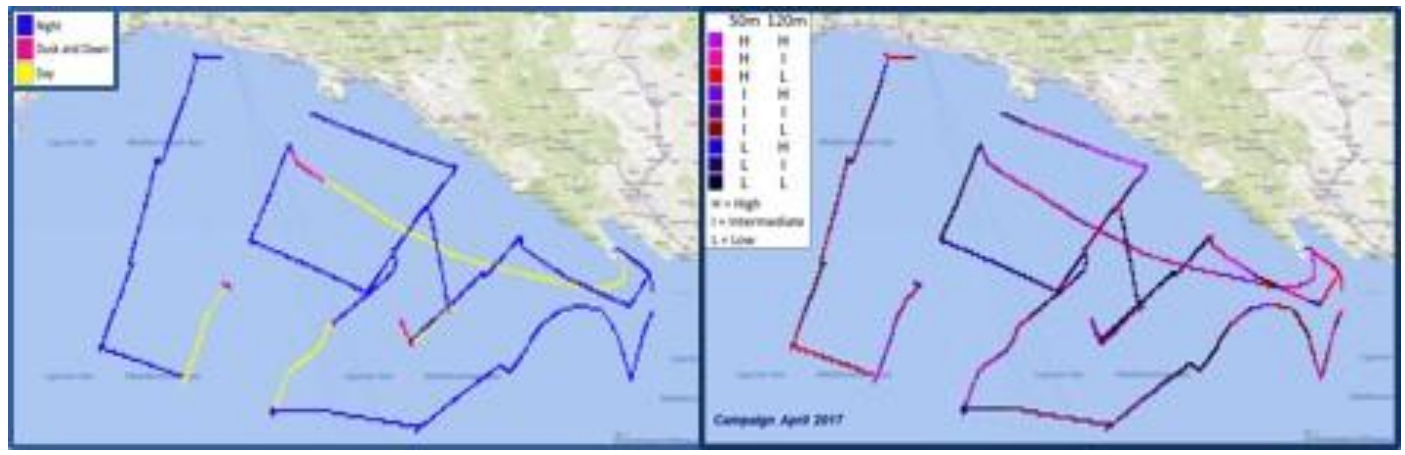

Figure 2. The track of 2017 campaign with representation of day/night (left) and surface/depth (right) backscatter intensity.

Data can be also selected to produce 2D horizontal maps or along-track vertical slices that can be referred to the position or to the time for a better characterization of migrating patterns .

The developed GIS-application to VM-ADCP backscatter data allows to visualize and analyse zooplankton distribution, giving added values to the acoustic data collected during oceanographic campaigns, facilitating the data management and supporting environmental studies 